\title{
A CAPACIDADE CIVIL DE EXERCÍCIO DE DIREITOS E A TOMADA DE DECISÃO APOIADA
}

\section{LEGAL CAPACITY FOR EXERCISE TO RIGHTS AND THE BACKING DECISION MAKING}

\author{
1Iara Pereira Ribeiro
}

\section{RESUMO}

Considerando a Lei Brasileira de Inclusão, o artigo apresenta a mudança na capacidade civil de exercício de direitos e examina o novo instituto da tomada de decisão apoiada, a partir dos institutos ao amministrazionde di sostegno (administrador de apoio) da Lei italiana ${ }^{\circ}{ }^{\circ}$, de 09 de janeiro de 2004 e do sistema de apoios do artigo 43 do Código Civil y Comercial argentino de 2015 e o projeto de lei para alteração da Lei Brasileira de Inclusão.

\section{Palavras-chave:}

Tomada de decisão apoiada; administrador de apoio; sistema de apoios, capacidade de exercício; capacidade civil

\begin{abstract}
Considering the brazilian law of inclusion, the article introduces the change in legal capacity for exercise and examine new institute of backing decision making in relation of the support administrator institute italian of law n 6, 2004 january 09 and the article 43 of support system of code civil and commercial argentine of 2015 and project for changing the brazilian law of inclusion.
\end{abstract}

\section{Keywords}

Legal capacity for exercise; backing decision making; support administrator institute Italian; support system of Code Civil and Commercial Argentine; civil capacity

\section{INTRODUÇÃO}

\footnotetext{
${ }^{1}$ Doutora em Direito pela Pontifícia Universidade Católica de São Paulo (PUC-SP), São Paulo, Brasil. Professora de Direito Civil pela Faculdade de Direito de Ribeirão Preto da Universidade de São Paulo (FDRP-USP), Ribeirão Preto, São Paulo, Brasil. Email: iararibeiro@usp.br
} 
A Convenção sobre os Direitos das Pessoas com Deficiência ingressou no ordenamento jurídico brasileiro com o status de emenda constitucional ${ }^{2}$. Entre as obrigações gerais que impôs aos Estados Partes se destaca o dever de modificar ou revogar leis dissonantes aos princípios da referida Convenção ${ }^{3}$. Para a efetivação desses direitos constitucionais foi promulgada a Lei 13.146, de 06 de julho de 2015, intitulada Lei Brasileira de Inclusão da Pessoa com Deficiência (ou ainda, Estatuto da Pessoa com Deficiência), em vigência desde o dia 3 de janeiro de 2016, provocando significativa mudança legislativa no Brasil.

Para cumprir a obrigação de adequação da legislação, a Lei Brasileira de Inclusão (LBI) alterou vários dispositivos legais do ordenamento jurídico brasileiro, com a finalidade de evitar antinomias, buscando harmonia entre as normas constitucionais e as legais. No âmbito do direito civil, a LBI alterou os dispositivos que tratavam do instituto da (in)capacidade civil, especificamente os artigos $3^{\circ}$ e $4^{\circ}$ do Código Civil, instituindo um novo paradigma sobre o tema e entre outras alterações, acrescentou novo capítulo ao Título IV do Código, ao criar a nova medida protetiva de Tomada de Decisão Apoiada (TDA).

O objetivo do artigo é apontar que o novo paradigma sobre a capacidade civil dignifica a pessoa e a protege, mesmo que de modo distinto ao da legislação revogada. Para tanto se analisa o sistema de proteção e apoio trazidos pela LBI, especificamente o novo instituto (o TDA), examinando-o em relação ao amministrazionde di sostegno (administrador de apoio/sustento) do direito italiano, previsto na Lei $n^{\circ}$ 6, de 09 de janeiro de 2004 e ao novíssimo Sistema de Apoios, previsto no artigo 43 do Código Civil y Comercial Argentino de 2015.

A relevância do assunto apresentado nesse estudo se justifica por ser imperioso evidenciar que a capacidade civil da pessoa natural deve estar em consonância com os direitos da personalidade e os direitos humanos e a tomada de decisão apoiada precisar se tornar instrumento eficaz para a proteção da pessoa na prática de atos e negócios jurídicos.

\footnotetext{
${ }^{2}$ A Convenção foi ratificada pelo Congresso Nacional por meio do Decreto Legislativo $\mathrm{n}^{\circ} 186$, de 09 de julho de 2008, em conformidade com o previsto no $\S 3^{\circ}$ do art. $5^{\circ}$ da Constituição Federal de 1988.

${ }^{3}$ Art. 4, alínea $b$, da Convenção: “1. (...) Para tanto, os Estados Partes se comprometem a: b) Adotar todas as medidas necessárias, inclusive legislativas, para modificar ou revogar leis, regulamentos, costumes e práticas vigentes, que constituírem discriminação contra pessoas com deficiência;”.
} 


\section{A nova visão do Regime Da (In)Capacidade}

Com a nova redação do artigo $3^{\circ}$ do Código Civil de 2002, somente o menor de dezesseis anos será considerado absolutamente incapaz. As outras duas hipóteses de incapacidade absoluta previstas deixaram de existir ${ }^{4}$, sendo que a previsão de incapacidade por não poder exprimir sua vontade, mesmo que por causa transitória, tornou-se uma das hipóteses de incapacidade relativa do artigo $4^{\circ}$ do Código Civil, juntamente com as hipóteses dos maiores de dezesseis e menores de dezoito anos, dos ébrios habituais, dos viciados em tóxicos e dos pródigos.

Já a hipótese de incapacidade absoluta daquele que por enfermidade ou deficiência mental não tiver discernimento para a prática de atos da vida civil, foi eliminada do ordenamento jurídico, bem como a previsão de incapacidade relativa dos que por deficiência mental tivessem o discernimento reduzido e a dos excepcionais sem desenvolvimento completo.

A eliminação dessas hipóteses coaduna a LBI com os ditames da Convenção sobre os Direitos das Pessoas com Deficiência ${ }^{5}$ (CDPD) e inova o direito civil pátrio sobre o regime da incapacidade civil, contrariando a doutrina nacional sedimentada sob a égide dos Códigos Civil de 1916 e o de 2002 (antes da alteração).

No novo paradigma do instituto da (in)capacidade civil há a diminuição da dicotomia entre capacidade jurídica (de direito, de gozo) e a capacidade de agir (de exercício, de fato, de

\footnotetext{
${ }^{4}$ O Art. $3^{\circ}$ do Código Civil, antes da alteração da Lei Brasileira de Inclusão (Lei 13.146, de 2015), estabelecia no rol dos absolutamente incapazes: I - os menores de dezesseis anos; II - os que, por enfermidade ou deficiência mental, não tiverem o necessário discernimento para a prática desses atos; III - os que, mesmo por causa transitória, não puderem exprimir sua vontade.

5 “Artigo 12 Reconhecimento igual perante a lei: 1. Os Estados Partes reafirmam que as pessoas com deficiência têm o direito de ser reconhecidas em qualquer lugar como pessoas perante a lei. 2. Os Estados Partes reconhecerão que as pessoas com deficiência gozam de capacidade legal em igualdade de condições com as demais pessoas em todos os aspectos da vida. 3. Os Estados Partes tomarão medidas apropriadas para prover o acesso de pessoas com deficiência ao apoio que necessitarem no exercício de sua capacidade legal. 4. Os Estados Partes assegurarão que todas as medidas relativas ao exercício da capacidade legal incluam salvaguardas apropriadas e efetivas para prevenir abusos, em conformidade com o direito internacional dos direitos humanos. Essas salvaguardas assegurarão que as medidas relativas ao exercício da capacidade legal respeitem os direitos, a vontade e as preferências da pessoa, sejam isentas de conflito de interesses e de influência indevida, sejam proporcionais e apropriadas às circunstâncias da pessoa, apliquem-se pelo período mais curto possível e sejam submetidas à revisão regular por uma autoridade ou órgão judiciário competente, independente e imparcial. As salvaguardas serão proporcionais ao grau em que tais medidas afetarem os direitos e interesses da pessoa. 5. Os Estados Partes, sujeitos ao disposto neste Artigo, tomarão todas as medidas apropriadas e efetivas para assegurar às pessoas com deficiência o igual direito de possuir ou herdar bens, de controlar as próprias finanças e de ter igual acesso a empréstimos bancários, hipotecas e outras formas de crédito financeiro, e assegurarão que as pessoas com deficiência não sejam arbitrariamente destituídas de seus bens." (Grifo nosso).
} 
obrar). Uma vez que do rol dos absolutamente incapazes, anteriormente previsto, restou como única hipótese a do menor de dezesseis anos.

A mudança parte da perspectiva que a capacidade não é mais determinada pelo estado de saúde da pessoa e sim pela sua situação de fato. O que pode limitar a capacidade da pessoa não é a deficiência intelectual, a doença mental originária ou adquirida, ou a perda parcial da cognição decorrente de doença senil, e sim, como a pessoa se encontra diante das decisões da vida que impactam na realização dos atos ou negócios jurídicos.

O que se busca nesse novo modelo, que não é criação originária do legislador brasileiro, mas resultado de um consenso internacional formalizado na referida Convenção ${ }^{6}$, é o ênfase no exercício dos direitos pela pessoa com deficiência, independente de sua deficiência $^{7}$, não se quer apenas proteger como era o escopo da legislação revogada, agora, o foco é ir além, é dar instrumentos para que a pessoa exerça sua capacidade de forma igualitária e plena.

Não assiste razão para quem entende que a pessoa com deficiência estará desprotegida nesse modelo. A proteção da realização de seus negócios se dará pela possibilidade de anulação, quando da eventual ocorrência dos vícios de vontade previstos no Código Civil de 2002, como erro, dolo, lesão, estado de perigo e coação e pelo dever de todo e qualquer contratante de agir conforme o princípio da boa-fé objetiva.

A alteração legislativa do regime da (in)capacidade para adequar Convenção e ordenamento jurídico interno ocorreu também na Argentina. O novo Código Civil e Comercial Argentino de 2014, promulgado também sob o impacto da Convenção, reconhece que a pessoa com deficiência tem capacidade jurídica em igualdade de condições com as demais pessoas em todos os aspectos da vida (Art. 12, 2 da CDPD). A igualdade entre pessoa

\footnotetext{
${ }^{6}$ Destaca-se que o Brasil ao entregar o $1^{\circ}$ Relatório nacional da República Federativa do Brasil sobre o cumprimento das disposições da Convenção sobre os Direitos das Pessoas com Deficiência 2008-2010, reconheceu no item 3 da parte específica do Relatório que com a ratificação da Convenção e seu Protocolo Facultativo, com equivalência de emenda constitucional, o Brasil assumiu o desafio de harmonizar seu arcabouço legal e adequar suas políticas públicas com a definição de deficiência consagrada pela Convenção. E que para cumprir a tarefa, implicava em revisão da conceituação de deficiência e incapacidade, bem como na adoção de nova metodologia de avaliação da deficiência e do grau de incapacidade para a vida independente e para o trabalho, utilizadas como parâmetros na concessão de benefícios vinculados aos programas e às ações afirmativas existentes (2010, p. 18).

${ }^{7}$ A LBI define pessoa com deficiência aquela que possui "impedimento de longo prazo de natureza física, mental, intelectual ou sensorial, o qual, em interação com uma ou mais barreiras, pode obstruir sua participação plena e efetiva na sociedade em igualdade de condições com as demais pessoas" $\left(\right.$ Art. $\left.2^{\circ}\right)$. Da definição legal infere-se que há várias deficiências, a deficiência intelectual é uma espécie e o intuito da lei é a igualdade de condições entre as pessoas na participação da vida em sociedade.
} 
com deficiência e sem deficiência quanto à capacidade reside na compreensão de que independentemente de característica pessoal ou até mesmo de diagnóstico médico presume-se ser a pessoa capaz.

Dispõe o art. 23 do atual Código Argentino sobre "Capacidad de ejercicio. Toda persona humana puede ejercer por sí misma sus derechos, excepto las limitaciones expresamente previstas en este Código y en una sentencia judicial." ${ }^{8}$. Na análise do dispositivo verifica-se que determina como regra geral a aptidão da pessoa humana para exercer por si só os direitos de que é titular. E permite, na parte final, certa flexibilidade ao conceito de incapacidade, para adaptar a situação de fato à pessoa, deixando de lado o antigo critério, que ao verificar estar a pessoa em uma das hipóteses, já a qualificava como incapaz (Lorenzetti, 2014, p.110).

No mesmo sentido, Rivera e Medina ao tratarem do conceito de capacidade no novo Código Argentino:

Atualmente a capacidade dos seres humanos não pode ser medida pelo mesmo critério com que foi aplicado séculos atrás. Assim, por exemplo, as decisões sobre próprio corpo, cuidado, liberdade, honra, privacidade, imagem e geral sobre todos direitos personalíssimos, devem ser tomadas de acordo com o grau particular de discernimento, compreensão e maturidade alcançada sem sujeitar a uma determinada faixa etária ou ao não padecimento de doenças mentais. A ideia que predomina sobre capacidade é afirmar a autonomia dos seres humanos para participar das decisões sobre si mesmo e, se for o caso, proteger os relativamente incapazes dos efeitos nocivos de uma má escolha, mediante um sistema abrangente de apoio que promova sua participação e não seu deslocamento (2016, p. 237, tradução nossa).

Para Ricardo Luis Lorenzetti, a presunção da capacidade implica na garantia de que a pessoa pode exercer seus direitos em qualquer circunstância, com exceção das hipóteses previstas expressamente no art. 32 do Código Civil e Comercial Argentino, mas que em caso de dúvida, a regra hermenêutica aplicada, é a do reconhecimento da capacidade (2014, p. 128).

\footnotetext{
${ }^{8}$ Diferentemente do Código revogado, que tal como os Códigos brasileiros de 1916 e 2002 (antes da LBI), indicava o rol dos incapazes, a saber: "Art. 54. Tienen incapacidad absoluta: $1^{\circ}$ Las personas por nacer; $2^{\circ}$ Los menores impúberes; $3^{\circ}$ Los dementes; $4^{\circ}$ Los sordomudos que no saben darse a entender por escrito;" (Codigo Civil de la Nación).
} 
Com isso, temos que a capacidade civil deve ser analisada sobre essa nova visão de exercício de direitos e de sistema de apoios para as possíveis escolhas da vida civil. Essa mudança se instrumentaliza na legislação brasileira pela tomada de decisão apoiada.

\section{Sistema de proteção e apoio às pessoas na realização dos atos civis}

A consequência prática de considerar uma pessoa absolutamente incapaz é de que para a realização de ato negocial, a sua manifestação de vontade não produz efeitos. A sua atuação na vida civil ocorre por representação, ou seja, quem manifesta a vontade é o representante, em quem se obriga é o representado, como se fosse ele próprio que houvesse agido.

O cerne do instituto da representação é que o representante está investido de um poder. O poder de praticar negócio jurídico, conforme sua vontade e juízo de conveniência, no lugar de outrem, repercutindo na esfera jurídica deste os efeitos do ato realizado. Existem duas formas de representação, a legal, que emana de determinação legislativa que impede o incapaz de atuar sozinho os atos da vida civil e a voluntária, que decorre de ato de vontade de pessoa capaz que autoriza outrem, por meio de mandato, a agir em seu nome e em limites determinados para a prática de negócio jurídico ao qual se obrigará.

Atualmente, o sistema de representação legal dos incapazes se restringiu à hipótese dos menores de dezesseis anos; em todas as outras situações a representação só ocorrerá de forma excepcional e limitada. No novo paradigma inaugurado pela Convenção, a LBI impõe a preservação da autonomia da pessoa e a criação de um sistema de proteção individualizado, sustentado no apoio e na decisão judicial de cada caso em particular.

\subsection{Tomada de Decisão Apoiada}

A determinação constitucional (dada pela Convenção) que a pessoa com deficiência goza de capacidade jurídica em igualdade de condições com as demais pessoas em todos os aspectos da vida (Art. 12, 2 da CDPD), impôs aos Estados Partes signatários o dever de concretizar esse direito de igualdade, criando medidas apropriadas para permitir que a pessoa 
com deficiência obtenha o apoio que necessitar para o exercício de sua capacidade (Art. 12, 3 da CDPD).

Entre as medidas inclusivas determinadas pelo legislador brasileiro, destaca-se a inovação trazida pela LBI de prever como medida protetiva, além da Tutela e Curatela, um novo instituto, ao qual nomeou "Tomada de Decisão Apoiada", inserindo um terceiro capítulo ao Título IV do Código Civil de 2002, com o acréscimo do Art.1783-A e parágrafos.

Tem-se apontado como fonte de inspiração do legislador para a criação do instituto, o amministrazionde di sostegno (administrador de apoio) inserido no direito italiano pela Lei $\mathrm{n}^{\mathrm{o}}$ 06, de 09 de janeiro de 2004 e /ou o artigo 43 do Novo Código Civil Argentino que define como apoio, "qualquer medida de caráter judicial ou extrajudicial que facilite à pessoa que o necessite, na tomada de decisão para dirigir sua pessoa, administrar seus bens e celebrar atos jurídicos em geral" (tradução nossa), o qual o legislador argentino denominou de "sistema de apoio ao exercício da capacidade".

\subsubsection{Amministrazionde di sostegno (administrador de apoio ou sustento)}

No instituto italiano a finalidade é a de limitar o menos possível a capacidade de agir de pessoa, garantindo sua autonomia para realização dos atos da vida cotidiana ${ }^{9}$. O mérito do instituto italiano é permitir ao juiz, por ofício ou a pedido da parte, substituir o pedido de interdição ou inabilitação pela administração de apoio, estabelecendo as medidas necessárias para efetivar a manutenção da autonomia da pessoa, sem que a interdição ou a inabilitação seja levada a efeito. Assim, a administração de apoio é uma nova medida de proteção, menos invasiva que a interdição ou inabilitação, que se coloca como alternativa dada ao magistrado de preservar ao máximo a capacidade de agir da pessoa para, apenas como última ratio, adotar as outras medidas (Bonilini e Tommaseo, 2008, p. 24).

A flexibilidade concedida ao magistrado de definir de modo casuístico a administração de apoio levando em conta às específicas necessidades do apoiado, dá ao instituto um caráter elástico e modular, autorizando até a possibilidade de se passar de uma a

\footnotetext{
${ }^{9}$ Legge 9 gennaio 2004, n. 6: Capo I: FINALITÀ DELLA LEGGE. Art. 1: 1. La presente legge ha la finalità di tutelare, con la minore limitazione possibile della capacità di agire, le persone prive in tutto $\mathrm{o}$ in parte di autonomia nell'espletamento delle funzioni della vita quotidiana, mediante interventi di sostegno temporaneo o permanente.
} 
outra medida, a administração de apoio à interdição, ou ao contrário, conforme se verifique no caso concreto, a ineficiência da medida $\operatorname{adotada}^{10}$ (Bonilini e Tommaseo, 2008, p. 24).

Comenta Moureira (2013, p. 244) que o interessante no instituto é de que nenhuma decisão judicial que o aplica é igual à outra. As decisões são moduladas e proporcionais conforme o caso concreto julgado.

Não nos parece, à primeira vista, que a inovação do direito italiano se assemelha à tomada de decisão apoiada, pois o legislador brasileiro dimensionou o instituto como forma de apoio a pessoas capazes com deficiência e requerido ao juízo por ela mesma, enquanto que o amministrazionde di sostegno surge como uma alternativa menos invasiva dada ao magistrado para proteção de pessoa incapaz. Contudo, não afastamos a possibilidade de que na prática jurídica os dois institutos se aproximem, pois a extensão do instituto italiano vem sendo definida e modificada pelos tribunais ${ }^{11}$.

\subsubsection{Sistema de apoio ao exercício da capacidade}

Estabelece o legislador portenho que é a pessoa maior de treze anos adicta ou que sofre de enfermidade mental suficientemente grave, de maneira que o exercício pleno de sua capacidade possa resultar em dano a ela mesma, ou a seus bens, deverá ter sua capacidade restringida.

Porém, ela não será considerada incapaz e nem lhe será nomeado curador. A medida adequada será o sistema de apoio ao exercício da capacidade, previsto no artigo 43 do Novo Código Civil Argentino ${ }^{12}$.

\footnotetext{
10 Hipótese de revogação expressamente prevista no Art. 413 do Código Civil Italiano, alterado pela Lei 6/2004 que instituiu o amministrazione di sostegno.

${ }^{11}$ Em sua tese, Moureira analisa decisões judiciais italianas sobre a aplicação do instituto (2013, p. 235 e segs).

${ }^{12}$ Artículo 43. Concepto. Función. Designación:
}

Se entiende por apoyo cualquier medida de carácter judicial o extrajudicial que facilite a la persona que lo necesite la toma de decisiones para dirigir su persona, administrar sus bienes y celebrar actos jurídicos en general.

Las medidas de apoyo tienen como función la de promover la autonomía y facilitar la comunicación, la comprensión y la manifestación de voluntad de la persona para el ejercicio de sus derechos.

El interesado puede proponer al juez la designación de una o más personas de su confianza para que le presten apoyo. El juez debe evaluar los alcances de la designación y procurar la protección de la persona respecto de eventuales conflictos de intereses o influencia indebida. La resolución debe establecer la condición y la calidad 
Esse sistema de apoio tem a finalidade de facilitar a tomada de decisão da pessoa que a ele se sujeita. $\mathrm{O}$ modelo a ser adotado deve ser construído conforme as circunstâncias e necessidades concretas. É possível estipular diferentes modalidades de apoio - conselho, auxílio, assistência e, para Lorenzetti, até mesmo, em último caso, representação (2014, p. 249).

Também quanto ao apoiador é possível estipular se será apenas uma pessoa, duas ou até mesmo, uma rede, se será um familiar ou um estranho. Importa que a decisão seja do apoiado, declarada conforme sua vontade e conveniência, mas que essa decisão tenha sido tomada com segurança e conhecimento dos efeitos.

As medidas de apoio poderão ter caráter judicial ou extrajudicial, moduladas pelo juiz, devendo a sentença ser inscrita no Registro de Estado Civil y Capacidad de las Personas.

Ensina Lorenzetti, que o sistema de apoio inaugurado pelo Novo Código Civil Argentino não se confunde com a curatela. Afirma que se substitui o modelo da curatela, baseado na identidade da pessoa, para um modelo de apoio, baseado na situação da pessoa (2014, p. 261).

A curatela é um modelo substitutivo, uma vez que se sustenta na representação, é a vontade do representante que prevalece para obrigar o representado. Enquanto que no sistema de apoio, se considera a situação de fato da pessoa para que a declaração de vontade manifestada seja a mais adequada ao conteúdo da sua real vontade.

\subsubsection{Análise dos dispositivos sobre a Tomada de Decisão Apoiada}

O instituto da tomada de decisão apoiada (TDA) é procedimento judicial de jurisdição voluntária pelo qual a pessoa com deficiência escolhe no mínimo duas pessoas para apoia-la em suas decisões. As pessoas eleitas para essa função deverão ser idôneas, ter vínculo com a pessoa apoiada e gozar de sua confiabilidade.

Considera-se que o legislador brasileiro poderia ter se inspirado no Art. 43 do Código Argentino para criar um mecanismo que permitisse o apoio ser dado por apenas uma pessoa, sendo o compartilhamento uma faculdade e não uma exigência.

de las medidas de apoyo y, de ser necesario, ser inscripta en el Registro de Estado Civil y Capacidad de las Personas. (Código Civil y Comercial de la Nación.) 
O mecanismo adotado pelo legislador pátrio, ao estabelecer duas pessoas, precisou prever a hipótese de divergência entre a pessoa apoiada e pelo menos um dos apoiadores. Nesse caso, se o negócio jurídico a ser realizado trouxer risco à pessoa apoiada ou prejuízo relevante ao seu patrimônio, será o juiz que deverá decidir sobre a questão, após ouvir o Ministério Público ( $\$ 6^{\circ}$ do Art. 1783-A). Sendo dever do apoiador divergente, apresentar a questão ao juízo, podendo se não o fizer responder por negligência.

Consideramos que a intervenção judicial para resolver a divergência entre a opinião dos apoiadores e apoiado é excessiva, vez que se o instituto é um procedimento facultativo, proposto por pessoa capaz. Ora, se é a própria pessoa que elege os apoiadores e determina os limites de atuação destes, e ainda, como previsto no $\S 9^{\circ}$ do referido artigo, a qualquer tempo, pode a pessoa apoiada solicitar o término do acordo firmado em processo de tomada de decisão apoiada, sem que precise sequer justificar as razões dessa solicitação, não é razoável submeter proposta de negócio à apreciação do juiz.

Vale ressaltar, ainda que na sistemática da lei, se o negócio for realizado sem a manifestação do juiz, será hipótese de anulação do negócio.

A preocupação do legislador em acomodar as opiniões do apoiado e apoiadores, judicializando o problema, pode ter como resultado o desinteresse de terceiro na realização do negócio, pois que oportunidade e conveniência interferem na celebração de contratos. Somado ao fato de ameaça de anulação, se realizado sem a autorização judicial.

Uma solução que poderia ter sido prevista pelo legislador seria a de considerar válido o negócio potencialmente arriscado realizado pela pessoa apoiada com a concordância de um dos apoiadores, com a condição de todos os apoiadores terem sido consultados. Ademais, o apoiador é pessoa de confiança do apoiado, sua função é de aconselhamento e não de determinação, é a vontade do apoiado que deveria prevalecer.

Ressalta-se que a lei não exige a assinatura dos apoiadores na celebração dos negócios jurídicos escritos, se o fizerem será como testemunha. Excepcionalmente deverão assinar, juntamente com o apoiado, se solicitado por terceiro com quem a pessoa apoiada realizar o negócio, especificando, por escrito, sua função em relação ao apoiado ( $\S 5^{\circ}$ do Art. 1783-A). A assinatura do apoiador tem a função de dar segurança para realização do negócio à outra parte, não o de consentir na realização. 
Sobre o procedimento para o deferimento do pedido de tomada de decisão apoiada, determina o $\S 3^{\circ}$ do art. 1783-A, que o juiz para se pronunciar sobre o pedido deverá ouvir o Ministério Público e, somente após essa oitiva, ouvirá pessoalmente o requerente e as pessoas que o apoiarão, sendo que nesse ato será assistido por equipe multidisciplinar.

Considera-se esse procedimento previsto burocrático e dissonante com os dispositivos da LBI. Ora, a pessoa que requer a tomada de decisão apoiada é plenamente capaz, assim não há razão para que seja ouvido o Ministério Público. Poderia a lei ter inovado ainda mais, e previsto um procedimento extrajudicial, já que o instituto funda-se na capacidade da pessoa.

Ressalta-se que é a pessoa a ser apoiada quem deve requerer a medida de tomada de decisão apoiada e indicar expressamente seus apoiadores, tratando-se, pois, de uma faculdade dada à pessoa com deficiência de determinar em quais situações da vida acredita necessitar de esclarecimentos ou subsídios para decidir e de se socorrer das considerações de apoiadores.

Finalmente, prescreve o $\S 4^{\circ}$ do Art. 1783-A que as decisões que a pessoa apoiada tomar terá validade e efeitos sobre terceiros, sem restrições, desde que esteja inserida nos limites do apoio acordado. O dispositivo trata de duas situações, uma que indica que a pessoa apoiada pode decidir sem restrições o que quiser; e outra, as situações em que o termo de tomada de decisão apoiada determinou necessário o aconselhamento de apoiadores. Nesse caso, a falta do requisito permitirá a anulação do ato realizado.

\section{Projeto de lei para a alteração da LBI no tocante à Tomada de Decisão Apoiada}

As inovações trazidas pela Lei Braileira de Inclusão surpreenderam a comunidade jurídica e surpreendentemente até mesmo o legislativo, que se apressou a apresentar o projeto de lei $\mathrm{n}^{\mathrm{o}} 757$, de $2015^{13}$ para alterar novamente os artigos $3^{\circ}$ e $4^{\circ}$ do Código Civil. Os senadores Antonio Carlos Valadares (PSB-SE) e Paulo Paim (PT-RS), autores do projeto de lei, justificam a iniciativa afirmando que a LBI retrocede ao negar às pessoas com deficiência o apoio de que porventura possam necessitar e por declarar civilmente capaz qualquer pessoa que esteja de fato inapta para, exercer sozinha, os atos da vida civil.

\footnotetext{
${ }^{13}$ Projeto apresentado no Senado Federal pelos Senadores Antonio Carlos Valadares (PSB-SE) e Paulo Paim (PT-RJ). Disponível em: http://www25.senado.leg.br/web/atividade/materias/-/materia/124251. Acesso em 25 de abril de 2016.
} 
O projeto de lei 757 de 2015 tem por objetivo alterar o Código Civil (Lei nº 10406, de 10 de janeiro de 2002), a Lei Brasileira de Inclusão (Lei n ${ }^{\circ}$ 13146, de 06 de julho de 2015) e o Código de Processo Civil (Lei n ${ }^{\circ}$ 13105, de 16 de março de 2015) para dispor sobre a igualdade civil e o apoio às pessoas sem pleno discernimento ou que não puderem exprimir sua vontade, os limites da curatela, os efeitos e o procedimento da tomada de decisão apoiada.

No tocante à TDA, o projeto de lei pretende incluir três parágrafos na regulamentação do instituto:

$\S 12$. Os negócios e os atos jurídicos praticados pela pessoa apoiada sem participação dos apoiadores são válidos, ainda que não tenha sido adotada a providência de que trata o $\S 5^{\circ}$ deste artigo.

$\S$ 13. Excepcionalmente, não será devida a tomada de decisão apoiada quando a situação da pessoa exigir a adoção da curatela.

$\S 14$. A tomada de decisão apoiada não será registrada nem averbada no Registro Civil de Pessoas Naturais. (NR)

A primeira proposta objetiva proteger os direitos de terceiro que adquirem bens da pessoa com deficiência. A providência ao qual se refere o $§ 5^{\circ}$ do Art. 1783-A é de assinatura conjunta dos apoiadores quando solicitado por terceiro. Cuida o legislador de explicitar que a falta de assinatura não será motivo de anulação. Contudo, na exegese do $\S 5$, já entediámos desse modo, pois que o dever de contra-assinar somente existiria se fosse solicitado.

Mais interesse produz a primeira parte do dispositivo ao propor que os atos e negócios serão válidos mesmo que a pessoa apoiada os pratique sem a participação dos apoiadores. O que significa "sem participação"? Sem conhecimento ou aconselhamento? Qualquer ato ou negócio jurídico, ou apenas os de pequeno valor?

Flavio Tartuce, em parecer sobre o referido projeto para o Senado Federal, posiciona-se a favor da proposta apresentada, nos seguintes termos:

A sugestão está na linha de um dos princípios do Código Civil de 2002, qual seja a eticidade, com a proteção da boa-fé, especialmente aquela de natureza objetiva, que diz respeito à lealdade dos participantes negociais (art. 113 do CC/2002). Vale lembrar que a boa-fé objetiva e o dever de cooperação processual passaram a ser princípios expressos também do Código de Processo Civil de 2015, estando a proposta entabulada com tais modificações, de cunho instrumental 
Quanto à proposta do $\S 13$, nos parece que é correto estabelecer que, bem se é caso de tomada de decisão apoiada, ou se é caso de curatela. Os dois institutos não podem existir conjuntamente. Porém, não está claro o porquê do legislador propor a palavra "excepcionalmente", consideramos que se for aprovado dessa maneira, será objeto de muitas dúvidas.

Finalmente, a proposta do $\S 14$ é de que a sentença de tomada de decisão apoiada não será registrada nem averbada no Registro Civil de Pessoas Naturais.

Flávio Tartuce, ao analisar o projeto, afirma que o "registro seria um requisito formal dispendioso e desnecessário, sendo certo que a operabilidade, outro dos princípios do Código Civil de 2002, indica que o material deve prevalecer sobre o formal". Nestes termos concordamos, contudo, lamentamos que o legislador não tenha previsto uma modalidade de tomada de decisão apoiada extrajudicial, o que nesse caso, seria imprescindível o registro. Vale apontar que o registro é exigível no Sistema de Apoios do Código Civil Argentino, conforme comentamos em item próprio.

Para corroborar a iniciativa do projeto de lei, os senadores citaram os artigos publicados em revistas eletrônicas pelos civilistas ${ }^{14}$ : José Fernando Simão ${ }^{15}$, Atalá Correia ${ }^{16}$, Vitor Frederico Kümpel e Bruno de Ávila Borgarelli ${ }^{17}$ que criticaram as alterações dos artigos $3^{\circ}$ e $4^{\circ}$ Código Civil.

Em oposição a esses entendimentos, outros autores, também em artigos publicados em revistas eletrônicas, se manifestaram favoravelmente ao novo regime das incapacidades como Pablo Stolze ${ }^{18}$, Flávio Tartuce ${ }^{19}$, Rodrigo da Cunha Pereira ${ }^{20}$.

\footnotetext{
${ }^{14}$ Esclarecemos que os autores citados no projeto não constam da referencia bibliográfica, pois os textos não foram objeto de análise no artigo.

${ }^{15}$ Estatuto da Pessoa com Deficiência causa perplexidade (Parte 1 e 2). Revista Consultor Jurídico. Coluna Opinião. Publicado em 06 e 07 de agosto de 2015, Disponível em <http://www.conjur.com.br/2015-ago07/jose-simao-estatuto-pessoa-deficiencia-traz-mudancas> Acesso em: 20 abr. 2016.

${ }^{16}$ Estatuto da Pessoa com Deficiência traz inovações e dúvidas. Revista Consultor Jurídico, Colunistas Direito Civil atual, 3 de agosto de 2015, 8h01. Disponível em http://www.conjur.com.br/2015-ago-03/direito-civil-atualestatuto-pessoa-deficiencia-traz-inovacoes-duvidas. Acesso em: 20 abr. 2016.

17 As aberrações da lei 13.146/2015. Migalhas. terça-feira, 11 de agosto de 2015. . Disponível em http://www.migalhas.com.br/dePeso/16,MI224905,61044-As+aberracoes+da+lei+131462015. Acesso em: 20 abr. 2016.

${ }^{18}$ STOLZE, Pablo. Estatuto da Pessoa com Deficiência e sistema de incapacidade civil. Revista Jus Navigandi, Teresina, ano 20, n. 4411, 30jul. 2015. Disponível em: <https://jus.com.br/artigos/41381>. Acesso em: 20 abr. 2016.

${ }^{19}$ Alterações do Código Civil pela lei 13.146/2015 (Estatuto da Pessoa com Deficiência). Repercussões para o Direito de Família e Confrontações com o Novo CPC. Parte I. Migalhas. Disponível em: <http://www.migalhas.com.br/FamiliaeSucessoes/104,MI224217,21048Alteracoes+do+Codigo+Civil+pela+lei+131462015+Estatuto+da+Pessoa+com>. Acesso em: 20 abr. 2016.
} 
O debate inaugurado por esses autores na web se estendeu para as salas de aulas, congressos de direito civil, associações de pais de deficientes intelectuais, para a sociedade civil em geral, chegando ao legislativo, que antes mesmo da entrada de vigência da Lei Brasileira de Inclusão apresentou o referido projeto de lei.

Espera-se que o projeto tramite e seja votado o mais breve possível para solucionar as questões mais polêmicas.

\section{CONCLUSÃO}

A Lei Brasileira de Inclusão deu uma nova perspectiva para capacidade civil, prevendo apenas como absolutamente incapaz o menor de 16 anos. Definiu a capacidade de agir, não mais pelo estado da pessoa (deficiente ou não), mas pela situação de fato desta pessoa frente aos atos e negócios civis.

O conceito atual de capacidade civil adequa-se a não discriminação, a política de inclusão e aos direitos humanos consagrados no século XX e XXI.

Esta mudança não tem um caráter local e sim global, os países representados nas Organizações das Nações Unidas deliberaram pela inclusão e pela capacidade civil plena a toda pessoa com deficiência. Em que pese as críticas e as casuísticas sobre essa mudança, parece-nos que não há possibilidade de retorno à situação anterior diante da relevância e prevalência Constitucional do tema.

E em decorrência da nova capacidade civil prevista no Código Civil de 2002, criouse a tomada de decisão apoiada, que apesar das similitudes apontadas com outros institutos alienígenas, possui características próprias e é forma de buscar a vontade de pessoa com deficiência plenamente capaz.

Tomada de decisão apoiada visa reconhecer e garantir os direitos da pessoa, pois é uma medida que define em quais atos ou negócios jurídicos será utilizada. Espera-se que se torne um instrumento eficaz para a capacidade de agir, propiciando à pessoa com deficiência o direito à autonomia da vontade.

\footnotetext{
${ }^{20}$ Lei 13.146 acrescenta novo conceito para capacidade civil. Revista Consultor Jurídico, 10 de agosto de 2015, 9h38. Disponível em: < http://www.conjur.com.br/2015-ago-10/processo-familiar-lei-13146-acrescentaconceito-capacidade-civil>. Acesso em: 20 abr. 2016.
} 
No que se refere ao Projeto de lei para modificar a LBI, em princípio, não se admite alteração ou retorno ao previsto anteriormente, uma vez que constitucionalmente a pessoa com deficiência é capaz nos termos da Convenção.

Eventual atividade legislativa, é interessante e necessária para o aperfeiçoamento no procedimento de tomada de decisão apoiada, visto ser esse o instrumento criado pelo legislador brasileiro para apoiar a formação da vontade que resultará na efetivação da capacidade de exercício. Com isso, entendemos que alterações de essência não seriam permitidas constitucionalmente, apenas as que determinem procedimentos ou formas do exercício da vontade da pessoa com deficiência.

\section{REFERÊNCIAS BIBLIOGRÁFICAS}

ARGENTINA. Código Civil y Comercial de la Nación. Ciudad Autónoma de Buenos Aires: Infojus, 2014.

BONILINI, Giovanni; TOMMASEO, Ferrucio. Dell'ammnistrazione di sotegno. In Collection Il codice civile. Commentario. Giuffrè, 2008.

FARIAS, Cristiano Chaves de; ROSENVALD, Nelson. Curso de direito civil: Parte Gral e LINDIB. V. 1. 14ª ed., Salvador, JusPodivm, 2016.

ITÁLIA. Legge 9 gennaio 2004, n. 6: Introduzione nel libro primo, titolo XII, del codice civile del capo I, relativo all'istituzione dell'amministrazione di sostegno e modifica degli articoli 388, 414, 417, 418, 424, 426, 427 e 429 del codice civile in materia di interdizione e di inabilitazione, nonchè relative norme di attuazione, di coordinamento e finali. Itália: Gazzetta Ufficiale n. 14 del 19 gennaio 2004. Disponível em: http://www.camera.it/parlam/leggi/040061.htm. Acesso em: 25/09/2016.

LORENZETTI, Ricardo Luis. Código Civil y Comercial de la Nácion Comentado. Tomo I: Arts. $1^{\circ}$ a 256. Santa Fé: Rubinzal-Culzoni, 2014.

MOUREIRA, Diogo Luna. Os desafios dos transtornos mentais e do comportamento para o direito civil: dialética do reconhecimento e sofrimento de indeterminação como pressupostos para a reconstrução da teoria das incapacidades. 2013. 273f. Tese (Doutorado). Pontifícia Universidade Católica de Minas Gerais. Programa de Pós-Graduação em Direito. Belo Horizonte, 2013. 
PEREIRA, Caio Mario da Silva. Instituições de direito civil. vol. I. 22a ed., Rio de Janeiro: Forense, 2008.

RIVERA, Julio César; CROVI, Luis Daniel. Derecho Civil: parte general. Ciudad Autónoma de Buenos Aires: Abeledo Perrot, 2016.

ROSENVALD, Nelson; FARIAS, Cristiano Chaves de. Curso de direito civil: Parte Gral e LINDIB. V. 1. 14ª ed., Salvador, JusPodivm, 2016.

SECRETARIA DE DIREITOS HUMANOS DA PRESIDÊNCIA DA REPÚBLICA (SDH). $1^{o}$ Relatório nacional da República Federativa do Brasil sobre o cumprimento das disposições da Convenção sobre os Direitos das Pessoas com Deficiência 2008-2010. Disponível http://www.sdh.gov.br/assuntos/pessoa-com-deficiencia/dados-estatisticosarquivo/relatorio-de-monitoramento-da-convencao-pdf-port Acesso em 25 set. 2016.

SECRETARIA DE DIREITOS HUMANOS DA PRESIDÊNCIA DA REPÚBLICA (SDH/PR)/SECRETARIA NACIONAL DE PROMOÇÃO DOS DIREITOS DA PESSOA COM DEFICIÊNCIA (SNPD). Novos Comentários à Convenção sobre os Direitos das Pessoas com Deficiência. $3^{\mathrm{a}}$ ed., SNPD - SDH-PR: Brasília, 2014.

TARTUCE, Flávio. Parecer ao Projeto de Lei do Senado Federal N. 757/2015. Altera o Estatuto da Pessoa com Deficiência, o Código Civil e o Código de Processo Civil. Disponível: http://www.senado.leg.br/atividade/rotinas/materia/getPDF.asp?t=195850\&tp=1. Acesso: 25 set. 2016.

TOBIAS, Jose W. Código Civil y Comercial Comentado. Tratado exegético: Glosas aos arts. 1 a 103. Jorge Horacio Alterini (Coord.). Ciudad Autónoma de Buenos Aires: La Ley, 2015.

TOMMASEO, Ferrucio; BONILINI, Giovanni. Dell'ammnistrazione di sotegno. In Collection Il codice civile. Commentario. Giuffrè, 2008. 